\title{
Alargar a visão, de figurantes a protagonistas da ação: notas introdutórias
}

\author{
Rosana Martins \\ Heloisa Buarque de Hollanda \\ Rodrigo Saturnino
}

O campo da Comunicação tem sido estudado a partir de variadas perspectivas. As pesquisas nesta área envolvem desde o universo robótico até as alterações éticas e morais na sociabilidade dos indivíduos que utilizam o Facebook. Sua importância como disciplina científica vem sendo testificada não apenas por meio de sua dimensão tecnoutilitarista, mas também pela forte influência que tem exercido na criação de novos valores e, do mesmo modo, na reorientação acerca da representação do mundo e, por conseguinte, de novas formas de interpretação do próprio self. Desta forma, a Comunicação, sendo as mídias um importante instrumento para sua práxis, é admitida como elemento estruturante da organização social e, portanto, como importante campo de estudos das Ciências Sociais (MARTINO, 2001). Entendida em seu sentido mais amplo como o processo de interação diversificada entre os indivíduos e as coisas, ela se transformou em um fervoroso campo de "disputas de poder", sendo utilizada não apenas por grandes corporações capitalistas, mas também como ferramenta discursiva a ser utilizada pelos mais variados grupos sociais interessados em seu uso como instrumento de afirmação e autorrepresentação identitátia no contexto de práticas culturais que se multiplicam em diversificação e pluralidade, tanto quanto na definição de seus lugares políticos e sociais.

Neste domínio celebrado com muito vigor pelos estudos culturais, autores como Hall (2002, 2003), Hoggart (1973), Willians (1993, 1994), Mattelart (2000, 2009), Certeau (2008), Martín-Barbero (1993, 1995) e Canclini (2003, 2005) voltaram sua atenção, cada um a seu modo, para a análise das diferentes modalidades comunicativas - colaborativas e expressivas - presentes no espaço público, que se tornaram práticas de resistência capazes de estabelecer novos arranjos subjetivos, novos modos de ser estar no mundo. Traços como esses acabaram apontando para uma nova mutação do sistema social em relação à autonomia da estrutura de produção e consumo em proposição na análise dos processos comunicacionais. Assim, estudos culturais têm apontado uma nova e desafiadora configuração no entendimento das práticas de comunicação tendo em vista identificar o receptor/ ator no espaço das múltiplas mediações (MARTíN-BARBERO, 1993).

Em síntese, a dimensão de passividade que lhe era atribuída pela verticalidade da emissão na comunicação massiva dá agora ao receptor a possibilidade de uma interatividade ativa como interlocutor, apto a produzir sentido e atuar no mundo como criador de sua realidade, a partir de formas colaborativas de produção e de comunicação, o que significa pensar no entendimento do lugar da cultura para além de vê-la como uma forma de conhecer e planejar, convertendo-a em lugar de transformação e inovação (CANCLINI, 2003).

A opção qualitativa que fizeram revigorou o "olhar embaçado" da academia a respeito da "imagem engessada do receptor" diante de sua condição de 
sujeito subordinadamente passivo. Os estudos destes autores proporcionaram o surgimento de um método científico interessado na interpretação da relação e da ação dos indivíduos com os dispositivos mediáticos. Um dos pontos de convergência destas pesquisas era refletir sobre o uso das mídias pelos sujeitos no percurso de empoderamento social como alternativa de subversão das lógicas utilitárias das chamadas indústrias culturais. 0 trabalho etnográfico realizado por Certeau (2008) serve como um bom exemplo deste processo. Ao analisar as táticas populares na produção alternativa de dispositivos destoantes dos princípios mercantilistas, deu destaque ao que denominou de "lógica da indisciplina", ou seja, aquela que é orientada por "formas sub-reptícias que são assumidas pela criatividade dispersa, tática e bricolada dos grupos ou dos indivíduos" (p. 41).

Neste sentido, cabe ressaltar que a mudança epistemológica acerca do protagonismo popular foi em muito intensificada com a abertura de acesso concedida pelas novas tecnologias da comunicação. Mixada com o posicionamento crítico dos grupos "periféricos", lembrando as palavras de Negri e Lazzarato (2001), a ação tem sido manifesta como

[...] potência autônoma e constitutiva dos sujeitos [desta forma, o movimento revolucionário que realizam, ao transformarem a instrumentalidade tecnológica em benefício próprio, emerge sob a forma de um] [...] antagonismo constitutivo da comunicação contra a dimensão controlada da própria comunicação. (p. 39)

É lugar comum admitir que o número de pessoas com acesso a diversas parafernálias eletrônicas aumenta paulatinamente. Também faz parte do imaginário popular interpretar a utilização destes artefatos pelo viés da comodidade e do entretenimento que eles oferecem. De fato, é verdade que a potencialidade da tecnologia ainda está restrita a um pequeno grupo de indivíduos com capital cultural, seguindo as ideias de Bourdieu (2006), superior à maior parte dos chamados utilizadores domésticos. No entanto, não é definitiva a afirmação que advoga o uso das tecnologias para um fim determinadamente apocalíptico. De um lado, a tecnofobia cibernética advinda dos contextos históricos da opressão capitalista por meio da invenção das máquinas ainda permanece como fantasma que aterroriza os sonhos dos humanistas; de outro, os tecnofílicos acríticos comemoram, antes do tempo, a realização fantasiosa e poética baseada na redenção do homem por meio de promessas científicas.

Na edição desse dossiê, originário do livro digital publicado em 2015 pelo Institut de la Comunicació UAB (InCom-UAB), da Universidade Autônoma de Barcelona, interessa-nos observar o hiato epistemológico que se formou no interior destas duas visões. Não quer dizer que o leitor encontrará nas páginas posteriores o equilíbrio entre as duas perspectivas, ao contrário, o exercício apresentado deixa evidente o caráter ambíguo da tecnologia das mídias. Por um lado, interpretada como dispositivo técnico, ela é reforçada como instrumento legitimado do processo comunicacional entre os indivíduos. Por outro lado, a tecnologia, entendida como dispositivo social, integra-se em um robusto quadro ideológico, forte o suficiente para imprimir suas formas sociais perante aqueles que as produzem e as utilizam. Sua intensa dependência deixa claro o quanto a sociedade incorporou a inteligência tecnológica nas suas formas de organização, ordem e controle social.

No intervalo entre essas duas abordagens, importantes fatores providenciaram a transformação da instrumentalidade tecnológica em benefício antagônico de grupos populares contra a dimensão controlada no processo da produção de discursos e, portanto, de sentidos. A digitalização da informação, o barateamento dos artefatos tecnológicos, a diminuição do fosso entre a linguagem técnica e os processos cognitivos e a gradativa inclusão digital fazem parte das contribuições técnicas que favoreceram a ruptura de alguns monopólios 
sustentados majoritariamente pelas elites corporativas. Sua fase contemporânea permitiu uma participação civil organizada, sem precedentes, de grupos outrora considerados "periféricos". O ingresso civil neste campo de disputa alimenta a comunicação como espaço pluralizante, ampliador da potência cívica e integrador de sujeitos em torno de causas comuns. Nesse sentido, a comunicação na era da informação é, portanto, poderosamente sinestésica (APPADURAI, 2004), pois propicia o surgimento de vivências orientadas para a descolonização do discurso hegemônico e da prática opressiva. A discussão ganha mais sentido e valor na medida em que representa positivamente a possibilidade de explorar esses aspectos de alteridade no campo da comunicação como um mecanismo de constituição de ações afirmativas e desafios globais que vão traçando novas configurações do mundo contemporâneo.

O desafio é apresentar uma nova agenda etnográfica capaz de providenciar visões críticas sobre a ação protagonista de coletivos e indivíduos, outrora subestimados por certo preconceito intelectual que ainda ecoa, silenciosamente, nos corredores acadêmicos e no olhar despótico das grandes mídias. Não se trata apenas de purificar o olhar turvo e desinteressado das políticas públicas no âmbito da comunicação alternativa, acima disso, esta coletânea pretende alargar a visão epistemológica acerca da função da comunicação no âmbito popular. Os casos do Brasil e de Portugal apresentados no livro, apesar dos diferenciados contextos de ação, afirmam sua conexão por meio da apropriação mediática que os indivíduos realizam. São ações de afirmação identitária elevadas pela ampliação do conhecimento e pela releitura constante de seu papel enquanto agente autônomo. São práticas mediáticas que sinalizam a decisão coletiva de se contrapor à redução de sua subjetividade em nome de rendimentos que forjam "crises", concentram o capital e produzem exclusões sistêmicas.

Nesse caso, esperamos que os estudos aqui reunidos possam ser um ponto de referência para dar visibilidade a estas práticas. A apropriação mediática e a autonomia comunicacional parecem ser premissas para a instauração de um saber, de um produzir e de um compartilhar. $O$ dossiê é composto por 14 ensaios temáticos escritos por autores portugueses e brasileiros de diferentes áreas das Ciências Humanas, tendo em comum o olhar voltado ao campo dos estudos culturais das mídias.

O primeiro ensaio é apresentado por Rosana Martins. O texto "Mídia comunitária e novas construções periféricas sociais no Brasil" reitera a dimensão política da produção audiovisual nas favelas do Rio de Janeiro e periferias de São Paulo. O objetivo é demonstrar a existência de uma dimensão política alinhada à noção de visibilidade na esfera pública com as ideias de autorrepresentação e de elaboração e difusão de discursos próprios por meio da produção audiovisual. O foco de análise é a produção discursiva veiculada nos materiais de divulgação desses coletivos. O texto identifica a existência e examina as características de uma produção audiovisual chamada "periférica" (e o discurso que a sustenta). $O$ texto desenvolve uma articulação teórica em torno dos conceitos de representação, políticas públicas, esfera da visibilidade pública e luta por reconhecimento. Desta forma, estabelece as bases de uma metodologia de análise da "arte e estética periférica" e de suas instâncias de produção e difusão. Das favelas e periferias surgem práticas de cultura, estéticas e redes de sociabilidade e política forjadas dentro dos guetos, mas conectadas aos fluxos globais. Essa experiência da cultura a partir dos movimentos socioculturais surge como possibilidades de uma renovação radical das políticas públicas. Trata-se de um modo de deglutição sóciopolítico-cultural, ou um modo de ressemantizar a sociedade e suas contradições ou reprocessar significados preexistentes.

No segundo, "A cobertura jornalística do Dia Internacional da Mulher na imprensa portuguesa: mudanças, persistências e reconfigurações", Carla Cerqueira e Rosa 
Cabecinhas partem para uma análise feminista das mídias, a qual, para as autoras, significa questionar as estruturas de poder hegemônicas que (re)produzem e sedimentam representações assimétricas e que têm repercussões na vida de todas as pessoas. Nesse sentido, assumindo o poder que os meios de comunicação possuem na atualidade, as autoras focam conclusões de uma análise da evolução da cobertura jornalística do Dia Internacional da Mulher desde 1975 até 2007, tendo como ponto de ancoragem as narrativas presentes em dois jornais diários nacionais: Jornal de Notícias e Diário de Notícias. A análise revela a existência de diversas mudanças, mas também de algumas persistências e reconfigurações nos discursos jornalísticos.

O terceiro ensaio, "Periferia ao vivo: democratização da mídia e socialização da informação por meio do hip-hop maranhense", de Rosenverck Estrela Santos, apresenta uma análise das relações entre a cultura hip-hop maranhense e as mídias e de como a juventude negra tem se organizado em meio a um cenário de desqualificação por parte da grande imprensa. Propõe reflexões acerca das atividades político-culturais do hip-hop em São Luís do Maranhão e suas ponderações sobre a democratização da mídia, bem como o papel desempenhado por esse movimento na constituição de uma prática político-educativa no sentido da formação de uma identidade étnico-racial e da produção de meios alternativos de comunicação.

No quarto, "A territorialização da informação: uma análise do jornalismo nas rádios locais portuguesas", Luís Bonixe observa como as rádios locais modificaram a paisagem midiática portuguesa. O texto mostra que a utilização da mídia alternativa aproximou os meios de comunicação dos cidadãos, gerando vínculos identitários no interior das comunidades em que se inseriam. Ao veicularem notícias e informações diretamente relacionadas com o cotidiano das populações locais, o jornalismo praticado nas rádios locais portuguesas parece ter fortalecido sentimentos de partilha e estreitado os laços sociais.

No quinto ensaio, "Mídia, políticas públicas e identidades: guerras ontológicas e comércio cultural no universo quilombola", Ana Stela de Almeida Cunha destaca que os estudos sobre o que se chama hoje de "quilombos" têm uma história bastante recente, não apenas referindo aqui a sua nomenclatura como também a todo o conteúdo a ela associado. Ainda que a "preocupação" com a presença primeiramente africana e mais tardiamente "mestiça", "crioula" - de milhares de indivíduos que chegaram maciçamente ao longo de séculos de escravidão tenha sido uma constante na história da formação brasileira, distintos modos de "olhar" e lidar com esta presença foram sendo lançados ao longo destes séculos. $\mathrm{O}$ texto reflete de que maneira estes modos de lidar com este segmento da população brasileira têm sido manipulados segundo os interesses de ambas as partes, tanto do Estado quanto das comunidades envolvidas, em um jogo dialético que envolve distintos atores e que tem como resultado políticas públicas relacionadas às questões de território e identidade, muitas vezes direcionadas ao que a autora denomina de "comércio cultural", envolvendo verdadeiras batalhas ontológicas.

A questão da imigração é tratada por Denise Cogo no sexto ensaio. No texto, intitulado "Internet e redes migratórias transnacionais: narrativas da diáspora no Brasil como país de imigração", a autora ressalta a intensa produção de discursos midiáticos a partir de 2007 com foco na imagem revigorada do Brasil como país de destino migratório. $O$ texto demonstra como a presença crescente de norteamericanos, espanhóis, portugueses, angolanos, haitianos e bolivianos, entre outras nacionalidades, mobilizou as mídias brasileiras a promover debates públicos em torno dos desafios que passaram a se colocar com a presença dos "novos" imigrantes. Nesse contexto, a autora observa a emergência de um ativismo midiático e propõe, por meio dos Estudos Críticos do Discurso, o estudo das narrativas produzidas e publicadas na internet por estes indivíduos, considerandoas lugares de evidência das múltiplas subjetividades que conformam o cotidiano e os processos de cidadania das migrações transnacionais. 
Em "Os cinemas que falam português: o conceito de cinema nacional, identidade e resistência", Leandro Mendonça aponta como o conceito de cinema nacional pode, muitas vezes, ser confundido com a existência de uma indústria nacional de cinema. Nesta direção, o texto analisa o conceito em suas relações com a ideia de modo de produção. $O$ texto também descreve a criação de um possível espaço dos cinemas falados em português e aborda a possibilidade de existência dessas cinematografias como espaços de resistência e de transferências culturais.

A cultura digital é tratada também no oitavo ensaio por Rodrigo Saturnino. 0 autor apresenta o novíssimo Partido Pirata e discute como o movimento reordena o sentido das próprias narrativas a partir de uma dinâmica específica que mistura elementos da figura mitológica dos piratas e as questões éticas e políticas que envolvem a chamada "pirataria digital". No texto, Saturnino demonstra como algumas ações afirmativas dos piratas se movem na tentativa de reordenar o olhar e os sentidos normativos da pirataria para, desta forma, fortalecer suas teses e afirmar uma nova identidade política.

Em "A validação do tecnobrega no contexto dos novos processos de circulação cultural", Lydia Gomes de Barros analisa o circuito paraense desse estilo musical que rompeu com alguns preconceitos elitistas acerca da chamada música "brega". O texto assinala o papel do tecnobrega na criação de um novo paradigma da música popular brasileira. Ao explorar a utilização das técnicas de remixagem e o acesso a recursos eletrônicos como dois importantes aspectos deste fenômeno social, a autora esclarece que o sucesso do tecnobrega está associado não apenas à fusão da música popular com batidas eletrônicas, mas também ao caráter independente de sua produção, potencializado pela imanência das tecnologias de informação.

A autonomia continua como tema transversal no décimo ensaio, intitulado "Os blogs como meios de comunicação política". No texto, Joaquim Paulo Serra trabalha a questão do jornalismo cidadão no contexto da Web 2.0. A proposta do autor é discutir a função social dos blogs como instrumentos que questionam a legitimidade do monopólio das mídias jornalísticas e dos jornalistas profissionais da grande imprensa na produção de notícias. De fato, a afirmação dos blogs foi se fazendo gradualmente, não por uma substituição das mídias jornalísticas tradicionais, mas por sua afirmação como meio tendente à complementação, aprofundamento e, muitas vezes, retificação da informação dessas mesmas mídias - e, assim, de enriquecimento da informação publicamente disponível. O capítulo ilustra essas importantes funções dos blogs com alguns exemplos recolhidos em uma amostra significativa de mídias jornalísticas e de blogs portugueses da área da política.

No décimo primeiro, "Devoções", Jorge Martins Rosa comenta a internet desde que se tornou um serviço acessível à generalidade do público, como um espaço que vive de paixões. Para o autor, por mais que as tecnologias e protocolos subjacentes evoluam - as modestas páginas pessoais do Geocities, as múltiplas gerações de fóruns de discussão, e em anos mais recentes também as redes sociais e outros serviços estafadamente descritos como Web 2.0 -, ainda encontramos na internet de tudo um pouco. Há sempre quem esteja disposto, quase de forma voluntária e sem fins lucrativos (pense no caso da Wikipédia e, em outro nível, no fenômeno dos torrents), a partilhar seus hobbies e obsessões. De forma invariável, mesmo nos interesses mais obscuros, devido ao efeito de escala desta rede global, podemos encontrar um vasto conjunto de outros indivíduos com preferências coincidentes, algumas vezes transvasando fronteiras nacionais, outras mantendo alguma especificidade local. Seguindo este raciocínio, a análise do autor propõe uma socioetnografia de um grupo do Facebook predominantemente português com um nome que quase poderia ser confundido com o de uma seita religiosa se não fosse tão óbvia sua ironia e no qual os membros são incentivados, a partir de um tema que muda diariamente, a mostrar seus conhecimentos da música pop rock contemporânea. 
Os dois ensaios seguintes enfatizam questões analíticas acerca das mudanças sociais ocasionadas pela intensa utilização das tecnologias. De um ponto de vista crítico teórico, José Luís Garcia, no décimo segundo ensaio, escreve sobre as influências da tecnologia no cotidiano social e as tendências econômicas orientadas para a transformação de importantes dimensões do conhecimento, da cultura e da comunicação em produtos destinados para um mercado global e competitivo. Em "Uma crítica da economia da informação na era das mídias digitais", o autor debruça-se sobre os riscos da instrumentalização técnica e da "informacionalização" da sociedade de modo sinérgico e acrítico. No texto, as dinâmicas e as mudanças nos modos de comunicação a partir do uso das tecnologias de informação são tratadas sob um olhar perspicaz que estimula as leitoras e leitores ao exercício interrogativo a respeito da excessiva dependência tecnológica das nossas sociedades.

No décimo terceiro, "A erosão da ideia de autoria", Heloísa Buarque de Hollanda aborda o surgimento da noção de autor ancorada nas teorias de Michel Foucault. Na primeira parte do texto, a ideia de autoria é tratada como uma funcionalidade cultural e comercial, construída historicamente. Na segunda, a autora reflete sobre o papel da autoria nos dias atuais. $O$ foco que escolheu recai sobre a mudança paradigmática que o conceito sofreu ao ser exposto às inovações das tecnologias digitais presentes em nosso cotidiano.

No ensaio convidado especialmente para esse dossiê e que fechará a obra (não apresentado originalmente no livro digital), "Novas convergências digitais: mídia, humanidades e artes", Francisco Rui Cádima retrata o contexto da cultura digital no momento de convergência em vários níveis. Nessa reflexão, explorase a narrativa de convergência multidisciplinar tanto no plano das estruturas interativas e hibridização de linguagens quanto no de produção e integração de tecnologias, tendo como objetivo pensar um modelo de "digital media" para as humanidades e artes. Esta reflexão passará pelo estado da arte das novas metodologias de criação e divulgação "web-based", configuradas em modelos inovadores de mediação e interação comunicacional.

As questões que emergem dos estudos e das análises que compõem o percurso editorial desta obra não esgotam as perspectivas acerca da função política das mídias e a prática "periférica" no processo de construção de novos modelos de produção cultural. Apesar da diversidade empírica e as particularidades teóricas que encontramos nos textos, as leitoras e leitores devem estar atentos às semelhanças e proximidades que interligam os diferentes contextos de ação, o que possibilita um diálogo entre narrativas disciplinares diversas e o confronto de investigações provenientes de diferentes sociedades.

Na organização da obra, colocamos a visão periférica em evidência e nos apropriamos dela como orientadora de nossos sentidos. Na ciência ótica, a visão periférica é aquela que capacita o indivíduo a enxergar pontos à sua frente e ao redor de seu campo visual. Apesar de sua aparente inferioridade se comparada à visão retilínea, que oferece maior riqueza de detalhes, a visão periférica é desfocante, mas é essencial para a nossa locomoção. Quando falta a luz, ela é a responsável por garantir a visão. Seguindo este raciocínio, os "olhares periféricos" neste livro não concentram sua visão em perspectivas dominantes, ao contrário, o exercício que promovem coloca em evidência que a identidade resulta das ações e das condições de produção do sujeito, efetivamente, de seu trabalho e da formação discursiva que provém igualmente das estratégias comunicacionais que ele usa para por em evidência. Os fenômenos sociais que se situam à margem das tendências estabelecidas destacam seu caráter inovador, experimental e alternativo no processo de elaboração de formas assimétricas da produção cultural. Neste sentido, apresentamos um exercício teórico e etnográfico do conjunto de 
contribuições plurais e multifacetadas que se refletem em um círculo dialético e permanente da construção de novos caminhos.

Boa leitura.

\section{Referências Bibliográficas}

AGGER, B. Cultural studies as critical theory. Londres: The Falmer Press, 1992.

APPADURAI, A. The capacity to aspire: culture and the terms of recognition. In: RAO, V.; WALTON, M. (Orgs.). Culture and public action. Stanford: Stanford University Press, p.59-84, 2004.

BOURDIEU, P. A economia das trocas simbólicas. 6. ed. São Paulo: Perspectiva, 2006.

CANCINI, N. G. A globalização imaginada. São Paulo: lluminuras, 2003.

- Culturas híbridas: estratégias para entrar y salir de la modernidad. Buenos Aires: Paidós, 2005.

CERTEAU, M. A invenção do cotidiano: 1. Artes de fazer. Petropólis: Vozes, 2008.

HALL, S. Representation: cultural representations and signifying practices. Londres: Sage, p. 13-74, 1997.

2003.

Da diáspora: identidades e mediações culturais. Belo Horizonte: UFMG,

. A identidade cultural na pós-modernidade. Rio de Janeiro: DP\&A, 2002.

HOGGART, R. As utilizações da cultura: aspectos da vida da classe trabalhadora, com especiais referências a publicações e divertimentos. Lisboa: Presença, 1973.

MARTINO, L. C. Globalização e sociedade mediática. In: NETO, A. F. et al. (Orgs.). Práticas midiáticas e espaço público. Porto Alegre: EDIPUCRS, 2001.

MARTín-BARBERO, J. De los medios a las mediaciones. 3. ed. México: G. Gilli, 1993.

América Latina e os anos recentes: o estudo da recepção em comunicação social. In: SOUZA, M. W. (Org). Sujeito, o lado oculto do receptor. São Paulo: Brasiliense, p. 39-67, 1995.

Tecnicidades, identidades y alteridades: desubicaciones y opacidades de La comunicación en el nuevo siglo. Revista Diálogos de la Comunicación, n. 64, p. 9-24, 2002.

MATTELART, A. Comunicacion y nueva hegemonia. Lima: Celadec, 1981.

. A globalização da comunicação. Bauru: EDUSC, 2000.

. A construção social do direito à Comunicação como parte integrante dos direitos humanos. Revista Brasileira de Ciências da Comunicação, v. 32, n. 1, jan./ jun., p. 33-50, 2009.

WILLIAMS, R. Culture is Ordinary. In: GRAY, A.; MCGUIGAN, J. (Orgs.). Studying culture: an introductory reader. Londres: Arnold, p. 5-14, 1993. 